\title{
ETEM-SG: Optimizing Regional Smart Energy System with Power Distribution Constraints and Options *
}

\author{
Frédéric Babonneau ${ }^{\dagger}$ \\ Michael Caramanis ${ }^{\ddagger}$
}

Alain Haurie ${ }^{\S}$

December 1, 2015

\begin{abstract}
This paper gives a detailed description of the ETEM-SG model, which provides a simulation of the long term development of a multi-energy regional energy system in a smart city environment. The originality of the modeling comes from a representation of the power distribution constraints associated with intermittent and volatile renewable energy sources connected at the transmission network like, e.g. wind farms, or the distribution networks like, e.g. roof top PV panels). The model takes into account the options to optimize the power system provided by grid friendly flexible loads and distributed energy resources, including variable speed drive powered CHP micro-generators, heat pumps, and electric vehicles. One deals with uncertainties in some parameters, by implementing robust optimization techniques. A case study, based on the modeling of the energy system of the "Arc Lémanique" region shows on simulation results, the importance of introducing a representation of power distribution constraints and options in a regional energy model .
\end{abstract}

${ }^{*}$ This research is supported by the Qatar National Research Fund under Grant Agreement no 61035-5-126.

†fbabonneau@ordecsys.com

${ }^{\ddagger}$ mcaraman@bu.edu

§ahaurie@ordecsys.com 


\section{Introduction}

This paper deals with the representation of power distribution constraints and options in a regional multi-energy systems analytic model akin to the MARKAL-TIMES family of models. The motivation for these developments is the modeling of the integration of energy systems in smart cities relying in particular on the co-optimization of the cyber and physical layers of the distribution power system (DPS). Increasing penetration of intermittent and volatile renewable energy sources connected at the transmission (e.g. wind farms) or the distribution networks (e.g. roof top PV panels) will impose new operational constraints. On the option side, the advent of grid friendly Flexible Loads (FL) and Distributed Energy Resources (DERs) including variable speed drive powered CHP micro-generators, heat pumps, and electric vehicles, provide opportunities to optimize power systems and improve operational and investment efficiencies. Indeed, DERs may have a profound impact on the resilience of network infrastructures.

We propose a modeling framework called ETEM-SG1, which is a "robust optimization" based capacity expansion model for an ensemble of energy related infrastructures that will be operated in a coordinated way in order to satisfy the demand for services in the urban community, with an optimal use of resources and reduced greenhouse gas (GHG) emissions. The model structure is inspired from MARKAL [18, 19] and TIMES [27]. This long-term expansion model is complemented by a model of electricity distribution, which reveals the future implicit prices on electricity markets under the conditions of massive penetration of renewables, grid storage and demand response. A representation of smart grids has already been introduced in the open-source energy modeling kit OSeMOSYS [25, 37], but our approach is different as one introduces a set of constraints and cost coefficients permitting a modeling of the power distribution in a smart grid environment. A detailed description of the modeling of a power distribution system, with smart grid operations, is given in [4]. In the present paper this modeling approach is integrated into the ETEM-SG energy model.

The service sectors considered include residential, commercial (HVAC, lighting, computing, electric appliances etc.), industry (process heat, machinery operation, ...), transportation (mass transit, private vehicles, public transportation,...), water supply and treatment, telecommunications and health. The infrastructure that will be considered encompass primary energy production and transformation of all relevant technologies, and networks such as water, gas, and electricity transmission and distribution (with emphasis on their interaction with renewable energy and other distributed resources). Appliances and energy use technologies will also be considered as part of a broadly construed energy infrastructure, and thus include transportation technologies, (e.g., electric, hydrogen fuel cell and other zero-emission vehicles), the various end-use technologies used in household appliances, commercial and industry energy uses, the water supply and treatment technologies and, indeed, the distributed communication

\footnotetext{
${ }^{1}$ This acronyme stands for Energy-Technology-Environment-Model with Smart Grids.
} 
and control technologies.

ETEM-SG provides a simulation of the evolution of final energy demand and of environmental impact of energy production and use in smart cities, when one takes full advantage of the potential of load shedding, demand response and integration of renewables provided by smart energy systems. In this modeling approach one assumes market efficiency at all time scales, with price information reflecting the real marginal cost of the various technologies participating in the supply-demand equilibrium for each energy form. The model is multi-energy, with a particular attention devoted to electricity and power system. The model takes into account the ability of Distributed Energy Resources (DERs: broadly construed, distributed flexible loads, generation and other resources) to provide reserves, reactive power compensation and shift their operation over time so as to reduce losses, congestion, wholesale energy costs and distribution asset (particularly transformer) wear and tear.

The paper is organized as follows. In Section 2, we present ETEM-SG, which is a multi-energy, long-term technology-rich capacity expansion model. In Section 3, we detail the modeling options adopted to represent the optimal exploitation of demand response, grid storage, electric car charging, distributed system reserve and reactive power compensation, under a massive penetration of renewables. In Section 4, we present a case study based on the Swiss region of "Arc Lémanique" and we show the impact of including the modeling of power distribution constraints and options on the simulations of optimal development paths. In Section 5 we conclude.

\section{The model ETEM-SG}

In this section we provide a complete description of the linear programming model ETEM-SG. The presentation is organized in three subsections devoted to the structure of the original open-source ${ }^{2}$ model ETEM, the introduction of demand-response activities, and the robustification of uncertain constraints, respectively.

\subsection{The structure of ETEM-SG}

ETEM is a linear programming model, which represents the optimal capacity expansion in production technology and the flow of resources in the whole energy system. In its standard version, the model is driven by exogenously defined useful energy demands, that is the demand for energy services, and imported energy prices. All technologies are defined as resource transformers and are characterized by technical coefficients

\footnotetext{
${ }^{2}$ ETEM is available as an open-source code that can be downloaded from the site urlww.ordecsys.com
} 
describing input and output, efficiency, capacity bounds, date of availability (for new technologies), life duration, et. Economic parameters define investment, operation and maintenance costs for each technology. The planning horizon is generally long enough to offer a possibility for the energy system to have a complete investment technology mix turnover. Typically ETEM simulates the development of an efficient regional energy system with a planning horizon of 30 to 50 years usually divided in periods of 1 to 5 years. In each period one considers a few typical days (e.g., 6 days corresponding to the three seasons - Winter, Summer, Spring-Fall - and two week day types - working weekday, weekend-Holiday -). Each of these days is subdivided into groups of hours, to obtain finally a set of timeslices that will be used to represent load curves and distribution of demand and resource availability in different seasons and at different time of the day.

The model is written in the modeling language AMPL [16] we give below, in pseudo code notations, a complete description of the model sets, parameters, variables, objective and constraints.

\subsection{Sets, parameters, and variables}

\subsubsection{Sets}

They provide a nomenclature of all the elements in the energy model.

$\Theta:$ set of periods

$S$ : set of timeslices

$C$ : set of commodities

$L:$ set of regions

$P$ : set of technologies

$P O L$ : set of emission types

$P \_P R O D[c] \subset P:$ set of technologies that are producing commodity $c \in C$

$P \_C O N S[c] \subset P$ : set of technologies that are consuming commodity $c \in C$

$P \_M A P[l] \subset P$ : set of technologies that are installed in region $l \in L$

$C_{-} M A P[p] \subset C$ : set of commodities that are input or output for technology $p \in P$

$C \_I T E M S[$ flow_act $[p]] \subset C$ : set of commodities in the activity flow

$C_{s}$ : set of storage commodities

$S U C C[s]$ : successive timeslice of $s \in S$ used for storage

\subsubsection{Parameters}

These are values that must be entered by the user. The complete definition of all the parameters constitutes the database of the model. 
Economic parameters: they are used to define the objective function.

disc_rate: Annual discount rate

nb_years $[t]$ : Number of years in period $t \in \Theta$

cost_icap $[t, p]$ : Unit cost of capacity increase for technology $p$ at period $t$

fixom $[t, p]$ : Fixed maintenance cost per unit of installed capacity for technology $p$ at period $t$

varom $[t, p]$ : Variable cost per unit of activity level for technology $p$ at period $t$

cost_imp $[t, s, c]$ : Unit cost of import for commodity $c$ in region $s$ at period $t$

cost_exp $[t, s, c]$ : Unit cost of export for commodity $c$ in region $s$ at period $t$

cost_deliv $[t, s, p, c]$ : Unit cost of delivery for commodity $c$ in technology $p$ in region $s$ at period $t$

$\operatorname{taxe}[t, \pi]$ : Unit emission tax for pollutant $\pi$ at period $t$

salvage $[t, p]$ : Salvage value (in \%) of technology $p$ that has been installed in period $t$

avail $[p]$ : Date of availability of technology $p$

life $[p]$ : Life duration of technology $p$.

\section{Parameters related to demands:}

network_efficiency $[c]$ : Global efficiency $(\leq 1)$ of distribution network for commodities other than electricity. The losses in the power distribution networks will be considered in the module representing the activities related to power distribution.

frac_dem $[t, s, c]$ : Fraction of (useful) demand for commodity $c$ occurring in timeslice $s$ of period $t$ demand $[t, c]$ : Useful demand for commodity $c$ in period $t$.

\section{Parameters related to technology capacities:}

avail_factor $[t, s, p]$ : Availability factor

cap_act $[p]$ : Capacity factor (translates power into energy)

fraction $[s]$ : Duration of time slice $s$ in fraction of year

fixed_cap $[t, l, p]$ : Residual capacity.

\section{Parameters defining bounds:}

act_bnd_lo $[t, s, l, p]$ : Lower bound on activity act_bnd_up $[t, s, l, p]$ : Upper bound on activity imp_tot_bnd_lo $[t, c]$ : Lower bound on import imp_tot_bnd_up $[t, c]$ : Upper bound on import exp_tot_bnd_lo[t $t, c]$ : Lower bound on export exp_tot_bnd_up $[t, c]$ : Upper bound on export cap_bnd_lo $[t, l, p]$ : Lower bound on capacity cap_bnd_up $[t, l, p]$ : Upper bound on capacity icap_bnd_lo $[t, l, p]$ : Lower bound on investment icap_bnd_up $[t, l, p]$ : Upper bound on investment. 


\subsubsection{Variables}

The decision variables are the following

COST: System cost (value of objective function)

$\operatorname{COM}(\Theta, S, L, P, C)$ : Activity level; production or consumption of commodity $C$ in region $L$ for process $P$ during timeslice $S$ at period $\Theta$

$\operatorname{ICAP}(\Theta, L, P)$ : Investment level (increase of capacity) for process $P$ at period $\Theta$ and in region $L$

$\operatorname{EXP}(\Theta, S, C)$ : Exports of commodity $C$ during timeslice $S$ at period $\Theta$

$\operatorname{IMP}(\Theta, S, C)$ : Imports of commodity $C$ during timeslice $S$ at period $\Theta$

$\operatorname{EMI}(\Theta, P O L)$ : Emission level of pollutant $P O L$ at period $\Theta$.

\subsection{Objective function}

The objective function is the total discounted system cost minus the salvage value of the residual life of equipments at the end of the planning period.

$$
\min \text { COST }
$$

with

$$
\begin{aligned}
& \mathbf{C O S T} \geq \sum_{t \in \Theta}(1+\text { disc_rate })^{- \text {nb_years }[t]}\left\{\sum_{l \in L, p \in P_{-} M A P[l]} \operatorname{cost\_ icap}[t, p] \mathbf{I C A P}[t, l, p]\right. \\
& +\sum_{l \in L, p \in P_{-} M A P[l]} \text { fixom }[t, p]\left(\sum_{k \in\{0 \ldots t\}:} \operatorname{ICAP}[t, l, p]\right. \\
& \operatorname{life}[p] \geq k+1 \\
& t-k \geq \operatorname{avail}[\mathrm{p}] \\
& \sum_{s \in S}\left(\sum_{l \in L, p \in P_{-} M A P[l]} \operatorname{varom}[t, p] \sum_{c \in C_{-} I T E M S[\text { flow_act }[p]]} \mathbf{C O M}[t, s, l, p, c]\right. \\
& +\sum_{c \in I M P} \text { cost_imp }[t, s, c] \mathbf{I M P}[t, s, c]-\sum_{c \in E X P} \text { cost_exp }[t, s, c] \mathbf{E X P}[t, s, c] \\
& \left.+\quad \sum \quad \text { cost_deliv }[t, s, p, c] \mathbf{C O M}[t, s, l, p, c]\right) \\
& l \in L, p \in P_{-} M A P[l], \\
& c \in C_{-} M A P[p] \\
& +\sum_{\pi \in P O L} \operatorname{taxe}[t, \pi] \mathbf{E M I}[t, \pi] \\
& \left.\sum_{\substack{l \in L, p \in P_{M} A P[l]: \\
t \geq \operatorname{avail}[p] \&(t+\operatorname{life}[p]) \geq T+1}} \text { salvage }[t, p] \times \operatorname{cost\_ icap}[t, p] \mathbf{I C A P}[t, l, p]\right\}
\end{aligned}
$$




\subsection{Constraints}

\subsubsection{Commodity balance equations}

For each commodity, or energy form other than electricity, what is produced or imported, at each time slice must be greater or equal to what is consumed or exported. The case of electricity will be treated in the module describing power distribution activities.

$$
\begin{aligned}
& \forall t \in \Theta, s \in S, c \in C \\
& \sum_{l \in L, p \in P_{-} P R O D[c] \cap P_{-} M A P[l]}(\mathbf{C O M}[t, s, l, p, c]+\mathbf{I M P}[t, s, c]) \times \text { network_efficiency }[c] \\
& \geq \sum_{\substack{l \in L, p \in P_{-} C O N S[c] \cap P_{-} M A P[l] \\
+\text { frac_dem }[t, s, c] \times \operatorname{demand}[t, c]+\mathbf{E X P}[t, s, c]}} \mathbf{C O M}[t, s, l, p, c]
\end{aligned}
$$

Capacity bounds production For each technology, what is produced is bounded by the available capacity.

$$
\begin{aligned}
& \forall t \in \Theta, s \in S, c \in C, p \in \mathrm{P} \_\mathrm{MAP}[l] \\
& \sum_{c \in C \_I T E M S\left[f l o w \_a c t[p]\right]} \operatorname{COM}[t, s, l, p, c] / \operatorname{act}_{f} \operatorname{lo}[p, c] \\
& <=\text { avail_factor }[t, s, p] \times \text { cap_act }[p] \times \text { fraction }[s] \times \\
& \left(\sum_{k \in 0 \ldots t: \operatorname{life}[p] \geq k+1, t-k \geq \operatorname{avail}[p]} \operatorname{ICAP}[t-k, l, p]+\text { fixed_cap }[t, l, p]\right)
\end{aligned}
$$

\subsubsection{Balance equations for commodity storage between time-slices}

For each storable energy, the amount of stored energy in a given timeslice is transferred to its successive timeslice with a reduction described by a loss factor storage_loss-factor. $\forall t \in \Theta, c \in C_{s}, s \in S$

$$
\begin{array}{r}
\left(\sum_{l \in L, p \in P_{-} P R O D[c] \cap P_{-} M A P[l]} \operatorname{COM}[t, s, l, p, c]\right) \times \text { storage_loss - factor }[c] \\
=\sum_{l \in L, p \in P_{-} C O N S[c] \cap P_{-} M A P[l], \sigma i n S U C C[s]} \operatorname{COM}[t, \sigma, l, p, c]
\end{array}
$$




\subsubsection{Activity bounds}

Exogenously defined bounds on activity. $\forall t \in \Theta, s \in S, l \in L, p \in$ P_MAP $[l]$

$$
\text { act_bnd_lo }[t, s, l, p] \leq \sum_{c \in C_{-} I T E M S[\text { flow_act }[p]]} \operatorname{COM}[t, s, l, p, c] \leq \text { act_bnd_up }[t, s, l, p]
$$

\subsubsection{Imports bounds}

Exogenously defined bounds on imports. $\forall t \in \Theta, s \in S, c \in C$

$$
\text { imp_tot_bnd_lo }[t, c] \leq \sum_{s \in S} \mathbf{I M P}[t, s, c] \leq \text { imp_tot_bnd_up }[t, c]
$$

\subsubsection{Export bounds}

Exogenously defined bounds on exports. $\forall t \in \Theta, s \in S, c \in C$

$$
\text { exp_tot_bnd_lo }[t, c] \leq \sum_{s \in S} \mathbf{E X P}[t, s, c] \leq \text { exp_tot_bnd_up }[t, c]
$$

\subsubsection{Capacity bounds}

Exogenously defined bounds on capacity. $\forall t \in \Theta, l \in L, p \in$ P_MAP $[l]$

cap_bnd_lo $[t, l, p] \leq \sum_{k \in 0 \ldots t: \operatorname{life}[p] \geq k+1 \& t-k \geq \text { avail }[p]} \operatorname{ICAP}[t-k, l, p]+$ fixed_cap $[t, l, p] \leq$ cap_bnd_up $[t, l, p]$

\section{Investment bounds}

Exogenously defined bounds on investment. $\forall t \in \Theta, l \in L, p \in$ P_MAP $[l]$

$$
\text { icap_bnd_lo }[t, l, p] \leq \operatorname{ICAP}[t, l, p] \leq \text { icap_bnd_up }[t, l, p]
$$




\subsubsection{Peak reserve equations}

Global reserve to cover peak load variations. These constraints impose that the total capacity of all processes producing a commodity at each time period and in each region must exceed the average demand in the time-slice where peaking occurs by a certain percentage. This constraint introduces a safety margin to protect against random events not explicitly represented in the model.

$$
\begin{aligned}
& \forall t \in \Theta, s \in S, c \in C \\
& 1 /(1+\text { peak_reserve }[t, s, c]) \times\left(\sum_{l \in L, p \in P_{-} P R O D[c] \cap P_{-} M A P[l]}\right. \\
& \text { cap_act }[p] \times \text { peak_prod }[p, s, c] \times \text { fraction }[s] \times \text { avail_factor }[t, s, p] \times
\end{aligned}
$$

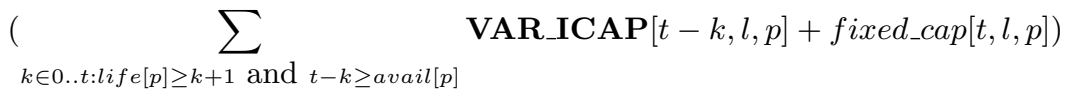

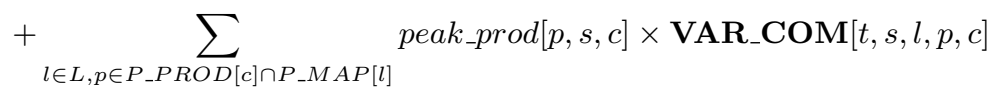

$$
\begin{aligned}
& \left.+\sum_{l \in L} \mathbf{V A R} \mathbf{I M P}[t, s, l, c]\right) \times \text { network_efficiency }[c] \\
& \sum_{l \in L, p \in P_{-} C O N S[c] \cap P_{-} M A P[l]} \underset{\mathbf{V A R}}{\geq} \\
& +\sum_{l \in L} \text { VAR_EXP }[t, s, l, c]
\end{aligned}
$$

Remark 1. This global reserve must be distinguished from the system reserve that we will introduce later on, when modeling the power distribution level, which has a role of coping with production variations intervening, in a fast time scale, due to intermittency of wind and solar generation.

\subsection{Representing demand-response in ETEM}

To model demand response one must allow the energy demands to adapt to implicit pricing signals. To do that the frac_dem parameters, which determine the proportions of demand that fall in each time slice, are replaced by decision variables, VAR_frac_dem. Since the frac_dem parameter enters linearly the equations of ETEM, it can be changed into a decision variable while staying in the realm of linear programming. Of course, new constraints have to be introduced to limit the possibility of demand displacement.

Additional constraint 1: $\forall t \in \Theta, S_{i}, c \in C$

$$
\sum_{s \in S_{i}} \text { VAR_frac_dem }[t, s, c]=\sum_{s \in S_{i}} f r a c \_d e m_{t}[t, s, c]
$$

where the $S_{i}$ 's are the seasons: $S_{1}$ is winter, $S_{2}$ summer and $S_{3}$ intermediate. These constraints ensure the entirety of the demand is met and forbid cross-seasonal load shifting. 
Additional constraint 2: $\forall t \in \Theta, s \in S, c \in C$

$$
\begin{aligned}
& \left(1-f r a c \_d e m \_d e v[t, s, c]\right) f r a c \_d e m[t, s, c] \leq \text { VAR_frac_dem }[t, s, c] \\
& \leq\left(1+f r a c \_d e m_{-} d e v[t, s, c]\right) f r a c_{-} d e m[t, s, c]
\end{aligned}
$$

where the frac_dem_dev $[t, s, c]$ parameter is the maximum allowed deviation from the nominal value of the fraction of demand, denoted by frac_dem $[t, s, c]$. This parameter can depend on $t$ since the share of the demand that can be shifted may evolve due to the progressive penetration of smart technologies.

\subsection{Robustification to deal with uncertain parameters}

ETEM-SG implements robust optimization methods to deal with uncertainty. We describe here the robustification technique used for two possible sources of uncertainty on (i) availability factors and (ii) new technology investment costs, respectively. We refer the reader to [2] for more details on robust optimization applied to ETEM constraints.

Robust optimization [8, 36] is an approach that essentially ensures that uncertain constraints in an optimization problem remain feasible for a whole set of possible realizations of random parameters. But, contrary to classical stochastic methods, robust optimization defines the set of possible realizations in an explicit way, e.g., as a polyhedron, rather than implicitly by means of a condition on a probability. This set of relevant realizations is called the uncertainty set. The salient feature of robust optimization is that it reformulates the uncertain constraint into plain inequalities, named the equivalent robust counterpart, that can be efficiently handled through convex optimization methods, and, in particular, linear programming. Application of robust optimization to energy and environment models is described in [5] and [6].

Let us first consider robust constraints for uncertain availability factors. A new parameter avail_factor_var $[t, s, p]$ represents the variability for availability factor of technology $p$ at period $t$ and timeslice $s$. The set P_rob contains technologies with uncertain availibilities. The approach consists in (i) adding a new constraint on total capacity utilization for a set of uncertain technologies and (ii) applying robust optimization techniques on this uncertain constraints. To robustify the model one thus introduces the two following sets of constraints : 
1. Total capacity utilization equation for uncertain technologies: $\forall t \in \Theta, s \in S, l \in L$

$$
\begin{aligned}
& \sum_{p \in \text { P_MAP }[l] \cap \text { P_rob, }} \sum_{c \in \text { C_ITEMS }[\text { flow_act }[p]]} \operatorname{COM}[t, s, l, p, c]<= \\
& \sum_{p \in \text { P_MAP }[l]: p \in \text { P_rob }}\left(\text { avail_factor }[t, s, p] \times \operatorname{cap} \_ \text {act }[p] \times \text { fraction }[s] \times\right. \\
& \left.\left(\sum_{k \in 0 . . t: \text { life }[p] \geq k+1, \& t-k \geq \text { avail }[p]} \operatorname{ICAP}[t-k, l, p]+\text { fixed_cap }[t, l, p]\right)\right) \\
& -\left(k_{1}[t, s, l] \times \mathbf{V}[t, s, l]+\sum_{p \in \text { P_MAP }[l] \cap \text { _rob }} \mathbf{U}[t, s, l, p]\right)
\end{aligned}
$$

2. Additional robust constraints: $\forall t \in \Theta, s \in S, l \in L, p \in$ P_MAP $[l] \cap$ P_rob

$$
\begin{aligned}
\mathbf{V}[t, s, l]+\mathbf{U}[t, s, l, p] \geq \text { avail_factor_var }[t, s, p] \times \text { avail_factor }[t, s, p] \times \text { cap_act }[p] \\
\times \text { fraction }[s] \times\left(\sum_{k \in 0 . t: \text { life }[p] \geq k+1, \& t-k \geq \text { avail }[p]} \mathbf{I C A P}[t-k, l, p]+\text { fixed_cap }[t, l, p]\right) ;
\end{aligned}
$$

Let cost_icap_var $[t, p]$ denote the variability factor of uncertain investment costs for technologies $p \in$ P_rob2. The robustification of the model leads to slightly modification of the objective cost function as

$$
\begin{aligned}
\text { COST } \geq & \ldots \text { same as above }(\text { see objective }(1)) \ldots \\
& +(1+\text { disc_rate })^{\text {nb_years }[t]} \times \sum_{t \in T}\left(k_{2}[t] \times \mathbf{V}_{\mathbf{2}}[t]+\sum_{p \in \text { P_rob2 }} \mathbf{U}_{\mathbf{2}}[t, p]\right)
\end{aligned}
$$

As for uncertain availability factors, additional robustification constraints are added to the ETEM model,

$$
\begin{aligned}
& \forall t \in \Theta, p \in \text { P_rob2 } \\
& \mathbf{V}_{\mathbf{2}}[t]+\mathbf{U}_{\mathbf{2}}[t, p] \geq \sum_{l \in L: p \in \operatorname{P\_ MAP}[l]} \text { cost_icap }[t, p] \times \text { cost_icap_var }[t, p] \\
& \times \mathbf{I C A P}[t, l, p] /(1+\text { disc_rate })^{\mathrm{nb}-\text { years }[t]} ;
\end{aligned}
$$

\section{Modeling distribution options and constraints}

In this section we focus on representation of the power distribution systems and the exploitation of flexible loads and DERs.

\subsection{Network description and assumptions}

Distribution activities and contraints in ETEM represent the management of centralized and distributed loads, storage and generation units for a local/regional power 
system at all periods and timeslices. Figure 1 summarizes the simplified topology of a distribution system. The $\infty$-bus $\left(b_{\infty}\right)$ corresponds to the substation and each down-

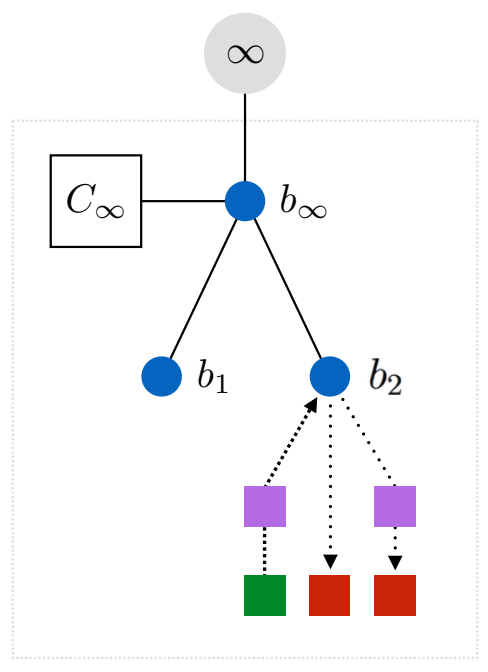

Figure 1: Representation of the power network. Circles denote buses, squares represent power electronics, flexible loads and distributed generators.

stream bus $\left(b_{1}\right.$ and $\left.b_{2}\right)$ corresponds to loads and DERs connected to a distribution feeder. The model's logic is as follows: Conventional generators and wind generators proposed by ETEM are located to bus $\infty$ and each distribution feeders corresponds to an ETEM region that is connected to bus $\infty$. Each feeder bus hosts $(i)$ demand corresponding to conventional loads (typically lighting), which consumes as a by-product "reactive power" whose magnitude depends on a constant power factor, (ii) flexible loads (typically EV battery charging, variable speed drive heat pumps for space conditioning), and (iii) PV generation. EV battery chargers and PV inverters can provide reactive power compensation as needed when they have excess capacity, i.e. when the sun does not shine or when the EV battery is not charging. During a given time slice, flexible loads produce value (or utility to their owners) by providing a service, such as space conditioning that maintains inside temperature within a comfort temperature zone, increasing the state of Charge of thee EV battery and the like.

Although other types of reserves are already modeled, e.g. in the peak reserve equations of ETEM, we focus now on secondary reserves made necessary by renewable generation and uncertainty in conventional loads and generation. The secondary reserve required by the system operator can be provided by conventional centralized generators but also by the flexible loads, in particular by the PHEV/EVs.

The model computes real power, reactive power and reserves associated with each region so as to satisfy load flow, voltage, energy balance and reserve requirement constraints. 
Assumption 1 The transmission network is made up of a single bus, i.e. transmission lines connecting centralized generators $G_{k}, k \in\{1, \ldots, K\}$, to the bus that supplies all distribution substations have negligible resistance.

Assumption 2 Each distribution feeder is represented by a single aggregated line and a single transformer with all of the demand and distributed resources and generation at the end of the line. The aggregated line has resistance and reactance parameters.

Assumption 3 Demand for energy services and ability for distributed generation or resource provision is specified as follows:

(i) For conventional demand at feeders, such as lights or non-storage/thermal demand, reactive power to be compensated is a given fraction $\gamma^{\text {react }}$ of produced real power.

(ii) For flexible/storage like loads, such as thermal storage buildings, space heating / conditioning, electric vehicles and the like, it is specified for the whole day. Contraints represents then the dynamics of state and and consumption.

(iii) For distributed resources that accompany electric vehicles or $P V$ generation, inverters and converters that are embodied can produce reactive power using excess capacity that they may have.

Assumption 4 Generator ramp constraints are negligible.

\subsection{Equations to describe power distribution}

We give below, in pseudo code notations, a complete description of the model sets, parameters, variables and constraints.

\section{Sets}

$\Theta_{d} \subset \Theta$ : set of periods for which distribution constraints are activated

$P_{\text {con }} \subset P$ : set of conventional load technologies

$P_{\text {flex }} \subset P$ : set of flexible load technologies

$P_{\text {gen } C} \subset P$ : set of centralized generation technologies

$P_{\text {gen } W} \subset P_{\text {genC }}:$ set of wind generation technologies

$P_{\text {gen }} \subset P$ : set of decentralized generation technologies

$P_{\text {gen } P V} \subset P_{\text {gen } D}:$ set of $\mathrm{PV}$ generation technologies. 


\section{Parameters}

resistance[l]: resistance (normalized to unity nominal voltage) of distribution feeder line $l \in L$.

reactance $[l]$ : reactance (normalized to unity nominal voltage) of distribution feeder line $l \in L$.

res: secondary system reserve factor.

$r e s^{w}$ : system reserve factor for wind generation.

$\gamma^{\text {react }}$ : Factor representing reactive power as a proportion of active power consumed by conventional inflexible loads.

$v[l]:$ Tension in feeder $l \in L$. The units are chosen so that the tension is normalized with value equal to 1 .

$\bar{\theta}[t, s, l], \underline{\theta}[t, s, l]:$ Lower and upper bounds on inside temperature of space conditioned facilities

$\theta^{\text {Ambient }}[t, s, l]:$ Ambient temperature

$\eta^{\text {loss }}[t, s], \eta^{\text {gain }}[t, s]:$ coefficients of heat gain or loss

$\bar{X}(\Theta, S, L)$ : Maximum discharge of EV batteries.

\section{Variables}

$D^{\text {con }}\left(\Theta, S, L, P_{\text {con }}\right)$ : Conventional demand load

$D^{\text {flex }}\left(\Theta, S, L, P_{\text {flex }}\right)$ : Flexible demand load

$D^{e v}(\Theta, S, L)$ : EV's demand load

$G^{\operatorname{dec}}(\Theta, S, L)$ : Decentralized power generation

$G^{\infty}(\Theta, S)$ : Centralized power generation

$I(\Theta, S)$ : Power imports

$P^{\infty}(\Theta, S)$ : Total real power provided by centralized technologies

$P^{\infty}(\Theta, S, L)$ : Real power provided by centralized technologies at feeders

$P^{\infty}\left(\Theta, S, P_{\text {gen } C}\right)$ : Real power provided by centralized technologies

$P(\Theta, S, L)$ : Real power load at feeders

$Q^{\infty}(\Theta, S)$ : Total reactive power provided by centralized technologies

$Q^{\infty}(\Theta, S, L)$ : Reactive power provided by centralized technologies at feeders

$Q^{\infty}\left(\Theta, S, P_{\text {gen } C}\right)$ : Reactive power provided by centralized technologies

$Q(\Theta, S, L)$ : Reactive power load at feeders

$Q^{e v}(\Theta, S, L)$ : Reactive power provided by EVs

$Q^{\text {flex }}\left(\Theta, S, L, P_{\text {flex }}\right)$ : Reactive power provided by flexible tecnhologies

$Q^{p v}\left(\Theta, S, L, P_{g e n P V}\right)$ : Reactive power provided by PVs

$R^{\infty}\left(\Theta, S, L, P_{\text {gen } C}\right)$ : Reserve provided by centralized technologies

$R^{\text {flex }}\left(\Theta, S, L, P_{\text {flex }}\right)$ : Reserve provided by flexible load

$C^{\infty}\left(\Theta, S, P_{\text {genC } C}\right)$ : Installed capacity of centralized technologies

$C^{\text {flex }}\left(\Theta, S, P_{\text {flex }}\right)$ : Installed capacity of flexible technologies

$\theta(\Theta, S, L)$ : inside temperature of space conditioned facilities

$X(\Theta, S, L)$ : State of discharge of EVs. 


\section{Constraints (from ETEM-SG to Distribution)}

This first set of constraints link the ETEM activity and capacity variables with the new variables introduced to describe distribution activities like, conventional and flexible demand loads, centralized and decentralized power generation, electricity imports to grids and installed DER capacities.

Demand load for conventional technology $p \in P_{\text {con }}$ at period $t \in \Theta_{d}, s \in S$ and feeder $l \in L$.

$$
\mathbf{D}^{\mathbf{c o n}}[t, s, l, p]=\mathbf{C O M}[t, s, l, p, \text { "ELC"]/cap_act }[p] / \text { fraction }[s] .
$$

Demand load for flexible technology $p \in P_{\text {flex }}$ at period $t \in \Theta_{d}, s \in S$ and feeder $l \in L$.

$$
\mathbf{D}^{\mathrm{flex}}[t, s, l, p]=\mathbf{C O M}[t, s, l, p, \text { "ELC"]/cap_act }[p] / \text { fraction }[s] .
$$

Demand load for EVs at period $t \in \Theta_{d}$, timeslice $s \in S$ and feeder $l \in L$.

$$
\mathbf{D}^{\mathbf{e v}}[t, s, l]=\mathbf{C O M}[t, s, l, \text { "EV", "ELC"]/cap_act }[p] / \text { fraction }[s] \text {. }
$$

Power generation from decentralized technology $p \in P_{\text {genD }}$ at period $t \in \Theta_{d}, s \in S$ and feeder $l \in L$.

$$
\mathbf{G}^{\mathbf{d e c}}[t, s, l, p]=\mathbf{C O M}[t, s, l, p, \text { "ELC"]/cap_act }[p] / \text { fraction }[s]
$$

Power generation from centralized technology $p \in P_{\text {genC }}$ at period $t \in \Theta_{d}$ and $s \in S$.

$$
\mathbf{G}^{\infty}[t, s, p]=\sum_{l \in L} \mathbf{C O M}[t, s, l, p, \text { "ELC"] }] / \text { ap_act }[p] / \text { fraction }[s]
$$

Electricity imports at period $t \in \Theta_{d}$ and timeslice $s \in S$.

$$
\mathbf{I}[t, s]=\mathbf{I M P}[t, s, " E L C \text { " }] / \text { cap_act }[p] / \text { fraction }[s]
$$

Installed capacity of centralized technology $p \in P_{\text {genC }}$ at $t \in \Theta_{d}$ and $s \in S$.

$$
\left(\sum_{k \in 0 \ldots t: \operatorname{life}[p] \geq k+1, t-k \geq \text { avail }[p]}^{\mathbf{C}^{\infty}[t, s, p]=\text { avail_factor }[t, s, p] \times \text { cap_act }[p] \times \text { fraction }[s] \times}\right.
$$


Installed capacity of flexible technology $p \in P_{\text {flex }}$ at $t \in \Theta_{d}$ and $s \in S$.

$$
\left(\sum_{k \in 0 \ldots t: \operatorname{life}[p] \geq k+1, t-k \geq \text { avail }[p]}^{\mathbf{C}^{\infty}[t, s, p]=\text { avail_factor }[t, s, p] \times \text { cap_act }[p] \times \operatorname{fraction}[s] \times} \mathbf{I C A P}[t-k, l, p]+\operatorname{fixed} \_c a p[t, l, p]\right)
$$

\section{Distribution constraints}

These constraints serve to compute real power, reactive power and reserves associated with each region and timeslice so as to satisfy load flow, voltage, energy balance and secondary reserve requirement.

Real power load at period $t \in \Theta_{d}, s \in S$ and feeder $l \in L$

$$
\begin{aligned}
\mathbf{P}[t, s, l]= & \sum_{p \in P_{\text {con }}} \mathbf{D}^{\mathbf{c o n}}[t, s, l, p]+\sum_{p \in P_{f l e x}} \mathbf{D}^{\text {flex }}[t, s, l, p]+\mathbf{D}^{\mathbf{e v}}[t, s, l, p] \\
& -\sum_{p \in P_{\text {gen } D}} \mathbf{G}^{\mathbf{d e c}}[t, s, l, p]
\end{aligned}
$$

Reactive power to be compensated at period $t \in \Theta_{d}, s \in S$ and feeder $l \in L$

$$
\begin{aligned}
\mathbf{Q}[t, s, l]= & \gamma^{\text {react }} \sum_{p \in P_{\text {con }}} \mathbf{D}^{\mathbf{c o n}}[t, s, l, p]-\sum_{p \in P_{\text {flex }}} \mathbf{Q}^{\text {flex }}[t, s, l, p] \\
& -\mathbf{Q}^{\mathbf{e v}}[t, s, l]-\sum_{p \in G e n P V} \mathbf{Q}^{\mathbf{p v}}[t, s, l, p]
\end{aligned}
$$

Total real power provided by centralized technologies at period $t \in \Theta_{d}$ and $s \in S$

$$
\mathbf{P}^{\infty}[t, s]=\sum_{p \in \text { GenC }} \mathbf{G}^{\infty}[t, s, p]+\mathbf{I}[t, s]=\sum_{l \in L} \mathbf{P}^{\infty}[t, s, l]
$$

Total reactive power provided by centralized technologies at period $t \in \Theta_{d}$ and $s \in S$

$$
\mathbf{Q}^{\infty}[t, s]=\sum_{p \in G e n C} \mathbf{Q}^{\infty}[t, s, p]=\sum_{l \in L} \mathbf{Q}^{\infty}[t, s, l]
$$

Real power provided by centralized technologies at period $t \in \Theta_{d}, s \in S$ and feeder $l \in L$

$$
\mathbf{P}^{\infty}[t, s, l]=\mathbf{P}[t, s, l]+\frac{\text { resistance }[l]}{v[l]^{2}}\left\{\mathbf{P}[t, s, l]^{2}+\mathbf{Q}[t, s, l]^{2}\right\}
$$

Reactive power provided by centralized technologies at period $t \in \Theta_{d}, s \in S$ and feeder $l \in L$

$$
\mathbf{Q}^{\infty}[t, s, l]=\mathbf{Q}[t, s, l]+\frac{\text { reactance }[l]}{v[l]^{2}}\left\{\mathbf{P}[t, s, l]^{2}+\mathbf{Q}[t, s, l]^{2}\right\}
$$


Remark 2. Linearized versions of Eqs (16)-(17) are obtained through a Taylor development in the neighborhood of the optimal solution.

$$
\begin{aligned}
\mathbf{P}^{\infty}[t, s, l]= & \mathbf{P}[t, s, l]+\frac{\text { resistance }[l]}{v[l]^{2}}\left\{\left(P^{0}[t, s, l]\right)^{2}+\left(Q^{0}[t, s, l]\right)^{2}+2 P^{0}[t, s, l](\mathbf{P}[t, s, l]\right. \\
& \left.\left.-P^{0}[t, s, l]\right)+2 Q^{0}[t, s, l]\left(\mathbf{Q}[t, s, l]-Q^{0}[t, s, l]\right)\right\} \\
\mathbf{Q}^{\infty}[t, s, l]= & \mathbf{Q}[t, s, l]+\frac{\text { reactance }[l]}{v[l]^{2}}\left\{\left(P^{0}[t, s, l]\right)^{2}+\left(Q^{0}[t, s, l]\right)^{2}+2 P^{0}[t, s, l](\mathbf{P}[t, s, l]\right. \\
& \left.\left.-P^{0}[t, s, l]\right)+2 Q^{0}[t, s, l]\left(\mathbf{Q}[t, s, l]-Q^{0}[t, s, l]\right)\right\}
\end{aligned}
$$

An updating scheme has to be implemented when using the linearized version. At each iteration $P^{0}$ and $Q^{0}$ are replaced by the last computed real and reactive power solutions. In practice, one converges very rapidly to a fixed-point (say 5-10 iterations).

Reserve provided by centralized and flexible loads at $t \in \Theta_{d}, s \in S$ and feeder $l \in L$

$$
\begin{array}{r}
\sum_{p \in P_{\text {gen } C}}(1+\alpha) \mathbf{R}^{\infty}[t, s, l, p]+\sum_{p \in P_{\text {flex }}} \mathbf{R}^{\text {flex }}[t, s, l, p] \geq \operatorname{res} \sum_{p \in P_{\text {con }}} \mathbf{D}^{\mathbf{c o n}}[t, s, l, p] \\
+\operatorname{res}^{w} \sum_{p \in P_{\text {gen } W}} \mathbf{G}^{\infty}[t, s, l, p]
\end{array}
$$

Capacity constraints on centralized generation $p \in P_{g} e n C$ at $t \in \Theta_{d}$ and $s \in S$

$$
\mathbf{R}^{\infty}[t, s, l, p] \leq \mathbf{P}^{\infty}[t, s, l, p] \leq \mathbf{C}^{\infty}[t, s, l, p]-\mathbf{R}^{\infty}[t, s, l, p]
$$

Capacity constraints on flexible loads $p \in P_{f} l e x$ at $t \in \Theta_{d}$ and timeslice $s \in S$

$$
\mathbf{R}^{\text {flex }}[t, s, l, p] \leq \mathbf{P}^{\text {flex }}[t, s, l, p] \leq \mathbf{C}^{\text {flex }}[t, s, l, p]-\mathbf{R}^{\text {flex }}[t, s, l, p]
$$

Bounds on reactive power compensation provided by flexible loads $p \in P_{\text {flex }}$ at $t \in \Theta_{d}$, $s \in S$ and $l \in L$

$$
0 \leq \mathbf{Q}^{\text {flex }}[t, s, l, p] \leq \mathbf{C}^{\text {flex }}[t, s, l, p]-\mathbf{P}^{\text {flex }}[t, s, l, p]
$$

State equations-1: Describe the dynamics of indoor temperature and the interval in which the temperature must remain when using to flexible heating technologies at $t \in \Theta_{d}, s \in S$ and $l \in L$

$$
\begin{aligned}
\theta[t, S U C C[s], l]= & \theta[t, s, l]+\eta^{\text {loss }}[t, s]\left(\theta^{\text {Ambient }}[t, s, l]-\theta[t, s, l]\right) \\
& -\eta^{\text {gain }}[t, s] \mathbf{P}^{\text {flex }}[t, s, l, p] \\
\underline{\theta}[t, s, l] \leq & \theta[t, s, l] \leq \bar{\theta}[t, s, l]
\end{aligned}
$$


State equations-2: Describe the dynamics and the minimum value of the state of discharge of EV's at $t \in \Theta_{d}, s \in S$ and $l \in L$

$$
\begin{aligned}
\mathbf{X}[t, S U C C[s], l]= & \mathbf{X}[t, s, l]+\operatorname{cap} \_a c t[p] \times \text { fraction }[s] \times\left(\mathbf{D}^{\mathbf{e v}}[t, s, l]\right. \\
& -\mathbf{P}^{\text {flex }}[t, s, l, \text { "EV"] }) \\
\mathbf{X}[t, s, l] \leq & \bar{X}[t, s, l] .
\end{aligned}
$$

\section{Case study}

We apply the model to a case study inspired from the regionl power system of the ArcLémanique region in Switzerland (Cantons of Vaud and of Geneva). We consider three distribution feeders corresponding, globally, to the three power distribution companies operating in the region. The energy model for three regions associated with the feeders is adapted from a previous ETEM model that had been developed for the whole region, without consideration of distribution constraints in previous projects ${ }^{3}$.

Remark 3. The objective of the numerical simulations is to illustrate the impact of introducing a representation of distribution constraints and options in a regional energy model, and not to provide a very precise representation of the energy policy choices in this region. Therefore the technical parameters used in the distribution module are not giving a very accurate description of the three distribution networks. This is the case, in particular, for the choice of a power factor of 0.93, similar to the one observed in US regions, associated with reactive power consumption by conventional loads of 0.35 $K$ Var for each $0.93 \mathrm{KW}$ that they consume.

\subsection{Linking with the Swiss Energy Strategy scenario Horizon - 2050}

The Swiss Federal Office of Energy (SFOE) has proposed a scenario for energy transition, called Neue Energiepolitik (NEP). It describes the Swiss Energy Strategy at horizon 2050 [11]. We use similar boundary assumptions to those in NEP for the three scenarios developed with ETEM-SG for the Arc Lémanique region. These scenarios will illustrate the importance of taking into consideration constraints and options at distribution level in the assessment of energy/climate policies at a regional scale. In particular, in the NEP scenario, the emissions of greenhouse gases are caped at a level of 1.5 tons of $\mathrm{CO}_{2}$-eq per person in 2050. Since the population is expected to attain 1.37 M people in the Arc Lémanique region by 2050 ('mittleres' Szenario A-00-2010), we impose as a constraint that the total 2050 emissions should not exceed $2.1 \mathrm{Mt} \mathrm{CO}_{2}$-eq in the region.

\footnotetext{
${ }^{3}$ We refer to the RITES [34] and TOU [3] projects, which were supported by the Swiss Federal Office of Energy.
} 
In the three scenarios the penetration of Variable Renewable Energies (VRE), that is $\mathrm{PV}$ and wind generation, is not limited. This allows us to evaluate the impact of power distribution constraints and options on the deployment of wind and solar technologies. The three scenarios are:

1. CMIT - a Climate MITigation scenario compatible with NEP assumptions on demands and emissions but obtained without distribution considerations in the ETEM model.

2. $C M I T_{P D C}$ - a $C M I T$ scenario with consideration of Power Distribution Constraints (on reserve, reactive power compensation, etc.) but without the options offered by DERs for system services (although PVs can contribute to reactive power compensation).

3. $C M I T_{P D C \& O}$ - a $C M I T$ scenario with consideration of Power Distribution Constraints and Options.

\subsection{Energy consumption in $\mathbf{2 0 1 0}$}

in 2010, the total annual energy consumption of the Arc Lémanique region was 114.3 P. 4 and, overall, $\mathrm{CO}_{2}$ emissions amounted to $5.48 \mathrm{Mt}$. The region is a net importer of electricity, around 5.5 TWh out of a total electricity consumption of 7.1 TWh in Year 2010 .

\subsection{Useful demands and timeslices}

Table 1 gives the useful demands considered in the case study and Figure 2 displays their assumed evolution up to 2050. These demands are then distributed on a yearly basis, among the 12 timeslices defined, for three seasons (Winter, Summer, Intermediate, and four parts of Day, Night, morning peak P1, Mid-Day and evening peak P2, as illustrated in Figure 3.

\footnotetext{
${ }^{4} 31.7$ TWh.
} 


\begin{tabular}{llll}
\hline Sector & Label & Code & Unit \\
\hline Residential & Heat Existing Buildings 2-9 appts & RA & PJ \\
& Heat Existing Houses & RB & PJ \\
& Heat New Buildings 2-9 appts & RC & PJ \\
& Heat New Houses & RD & PJ \\
& Appliances & R1 & PJ \\
& Lighting & RL & PJ \\
\hline \multirow{2}{*}{ Transport } & Public Transports: Bus & TA & tkmv/d \\
& Public Transports: Tramway & TB & tkmv/d \\
& Public Transports: Train & TC & tkmv/d \\
& Public Transports Misc. & TD & tkmv/d \\
& Automobile & TE & tkmv/d \\
& Truck & TH & tkmv/d \\
& Delivery vehicles & TL & tkmv/d \\
\hline \multirow{2}{*}{ Industry } & Food, textile, wood, paper, edition & RNH & PJ \\
& Chemistry, rubber, glass, metal & RCI & PJ \\
& Machine manufacturing, equipments & RMA & PJ \\
& Construction & RCO & PJ \\
& Tertiary & RTR & PJ \\
& Other & RAL & PJ \\
\hline
\end{tabular}

Table 1: Useful demands classification (PJ means PetaJoule and tkmv/d means thousand $\mathrm{km}$ vehicle per day).
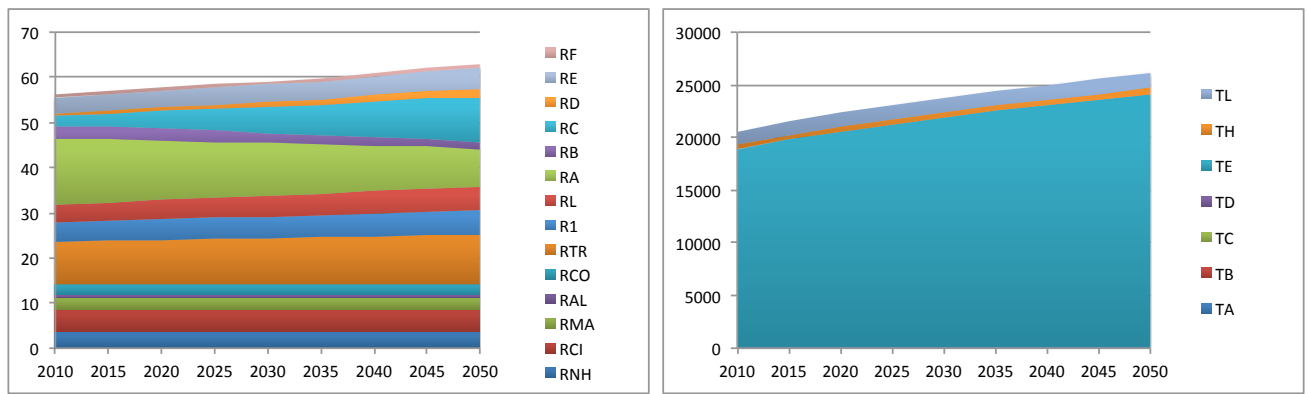

Figure 2: Evolution of useful demands in PJ (left) and in tkmv/d (right).

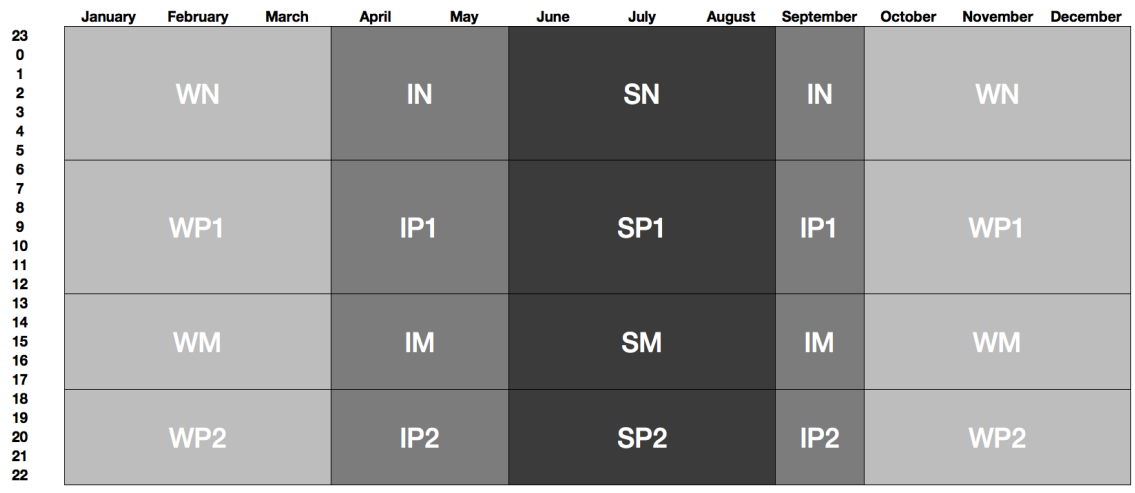

Figure 3: Definition of timeslices 


\subsection{Portfolio of technologies}

Table 2 gives the list of all electricity production or consumption technologies that appear in the model.

\begin{tabular}{|c|c|c|c|}
\hline Category & Label & Code & Comment \\
\hline Centralized production & $\begin{array}{l}\text { Hydro power plant } \\
\text { Windmill } \\
\text { Gas Turbine } \\
\text { Veytaux (existing turbine) } \\
\text { Veytaux (pump) } \\
\text { Tridel Thermal Plant } \\
\text { Tridel Plant (Electricity) } \\
\text { Pierre-de-Plan Plant (heat+electricity) } \\
\text { Lignon Plant (heat) } \\
\text { Chatillon Plant (heat) } \\
\text { Cheneviers Plant (heat and electricity) } \\
\text { Geothermy Plant } \\
\text { Enerbois Plant } \\
\text { Industrial Cogen. Turbine (5 MW) } \\
\text { Industrial Combined Cycle (5 MW) } \\
\text { Cogeneration } \\
\text { Gas combined power plant } \\
\text { Oil-Fired Steam-Cycle } \\
\text { Gas CC (CHP) } \\
\text { Oil-Fired Steam-Cycle (CPD) } \\
\text { Gas fuel cell }\end{array}$ & $\begin{array}{l}\text { E01, E02 } \\
\text { E08 } \\
\text { E0E } \\
\text { E00 } \\
\text { E0P } \\
\text { TIT } \\
\text { TIE } \\
\text { PDP } \\
\text { LIG } \\
\text { CHA } \\
\text { ECH } \\
\text { ERG } \\
\text { ERB } \\
\text { E6A, E6B } \\
\text { E6C } \\
\text { E90, E9G, E9R } \\
\text { E0F } \\
\text { E0D } \\
\text { EB1 } \\
\text { EB2 } \\
\text { EB3 }\end{array}$ & $\begin{array}{l}\text { Existing } \\
\text { Existing } \\
\text { Existing } \\
\text { Existing } \\
\text { Existing } \\
\text { Existing } \\
\text { Existing } \\
\text { Existing } \\
\text { Existing } \\
\text { Existing } \\
\text { Existing } \\
\text { Existing } \\
\text { Existing } \\
\text { Existing } \\
\text { Existing } \\
\text { Existing } \\
\text { New } \\
\text { New } \\
\text { New } \\
\text { New } \\
\text { New }\end{array}$ \\
\hline Decentralized production & $\begin{array}{l}\text { Photovoltaic } \\
\text { Existing CHP } \\
\text { Advanced CHP }\end{array}$ & $\begin{array}{l}\mathrm{E} 07 \\
\mathrm{RAC} \\
\mathrm{RCC}\end{array}$ & $\begin{array}{l}\text { Existing } \\
\text { New } \\
\text { New }\end{array}$ \\
\hline Conventional loads & $\begin{array}{l}\text { Industry } \\
\text { Appliances } \\
\text { Lighting } \\
\text { Electric and solar warm water } \\
\text { Electric heaters } \\
\text { Geothermal heaters } \\
\text { Public transport (Train, tramway, } \\
\text { bus, miscellaneous, etc) }\end{array}$ & $\begin{array}{l}\text { NHT, CHT MAT, } \\
\text { ALT, COT, TRT } \\
\text { R11 } \\
\text { RCL } \\
\text { RE1, RE2, RE3, } \\
\text { RF1, RF2, RF3 } \\
\text { RFD } \\
\text { RA7, RB7, RC7, } \\
\text { RD7 } \\
\text { RCG } \\
\text { TA2, TB1, TC1 } \\
\text { TD1 }\end{array}$ & $\begin{array}{l}\text { Existing } \\
\text { Existing } \\
\text { Existing } \\
\text { Existing } \\
\text { Existing } \\
\text { Existing } \\
\text { Existing } \\
\text { New } \\
\text { New } \\
\text { New } \\
\text { Existing } \\
\text { Existing }\end{array}$ \\
\hline Flexible loads & $\begin{array}{l}\text { Electric Heat pump for builings } \\
\text { Electric Heat pump for houses } \\
\text { Electric Heat pump for new builings } \\
\text { Electric Heat pump for new houses } \\
\text { Electric vehicles (EVs) }\end{array}$ & $\begin{array}{l}\text { RAT } \\
\text { RBT } \\
\text { RCT } \\
\text { RDT } \\
\text { TES }\end{array}$ & $\begin{array}{l}\text { New } \\
\text { New } \\
\text { New } \\
\text { New } \\
\text { New }\end{array}$ \\
\hline
\end{tabular}

Table 2: Portfolio of electricity-based technologies by category. 


\subsection{Analysis and comparison of the scenarios}

To compare the simulations results for the three scenarios $\left(C M I T, C M I T_{P D C}\right.$ and $\left.C M I T_{P D C \& O}\right)$, we concentrate on the time interval 2025-2050, since it is when the VRE technologies will have the possibility to penetrate strongly the energy system.

Figure 4 shows the evolution of the power supply mix for the three scenarios. The scenario $C M I T$ is the one that would be proposed by a TIMES or ETEM model, when there is no limit for the penetration of VREs and no consideration of secondary reserve requirement associated to VREs nor reactive power compensation. Simulation results show that the stringent emission constraint is satisfied mainly by a strong deployment of wind farms (see E08 in Figure 4), i.e. $72 \%$ of total electricity generation, and of electric heat pump in the heating sector (see RAT and RCT in Figure 5). Penetration of EVs is not needed in that situation (see TES in Figure 6). This scenario is of course not realistic as a power distribution system with $72 \%$ VRE generation would face serious resilience and stability issues. So, in practice, in the use of these existing models one should introduce some arbitrary constraints limiting the proportion of VRE generation to a range of 30 to $40 \%$.

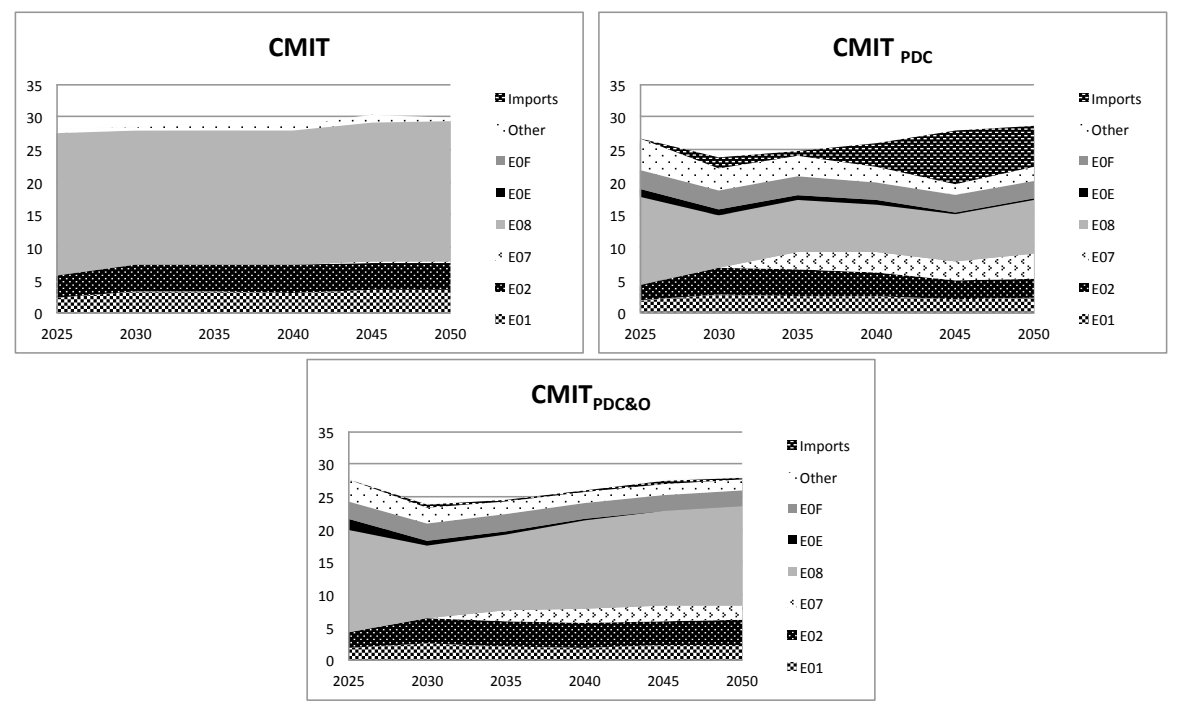

Figure 4: Evolution of electricity production and use (in PJ/Y).

The scenario $C M I T_{P D C}$ confirms that power distribution constraints have a significant impact on VRE penetration. The share of VREs, i.e. wind farms (E08) and PVs (E07) decreases to $40 \%$ of total electricity generation as shown in Figure 4 . This is consistent with the current practice, alluded to above, which recommends a maximum $30-40 \%$ share for VRE generation. Compared to scenario CMIT we observe a larger penetration of solar panels due to their property of reactive power compensation. The other production technologies are gas combined-cycle power plants (E0F), 
gas turbines (E0E) and hydro power plants (E01 and E02). We notice that imports, assumed to be carbon free in this exercise, are needed in scenario $C M I T_{P D C}$ to satisfy the emissions reduction constraint. These imports come from Europe and other regions of Switzerland and are not distinguished in the model. We observe in Figure 6 that, in both scenarios with power distribution constraints $\left(C M I T_{P D C}\right.$ and $\left.C M I T_{P D C \& O}\right)$, EV technology (TES) is much needed to reach the GHG emissions reduction objectives. The other types of car used are hybrid (THY) and diesel (TE1) vehicles. In the residential sector, the situation for heating is very similar in these scenarios with investment in heat pumps technologies (i.e., around $20 \%$ of the heating sector).

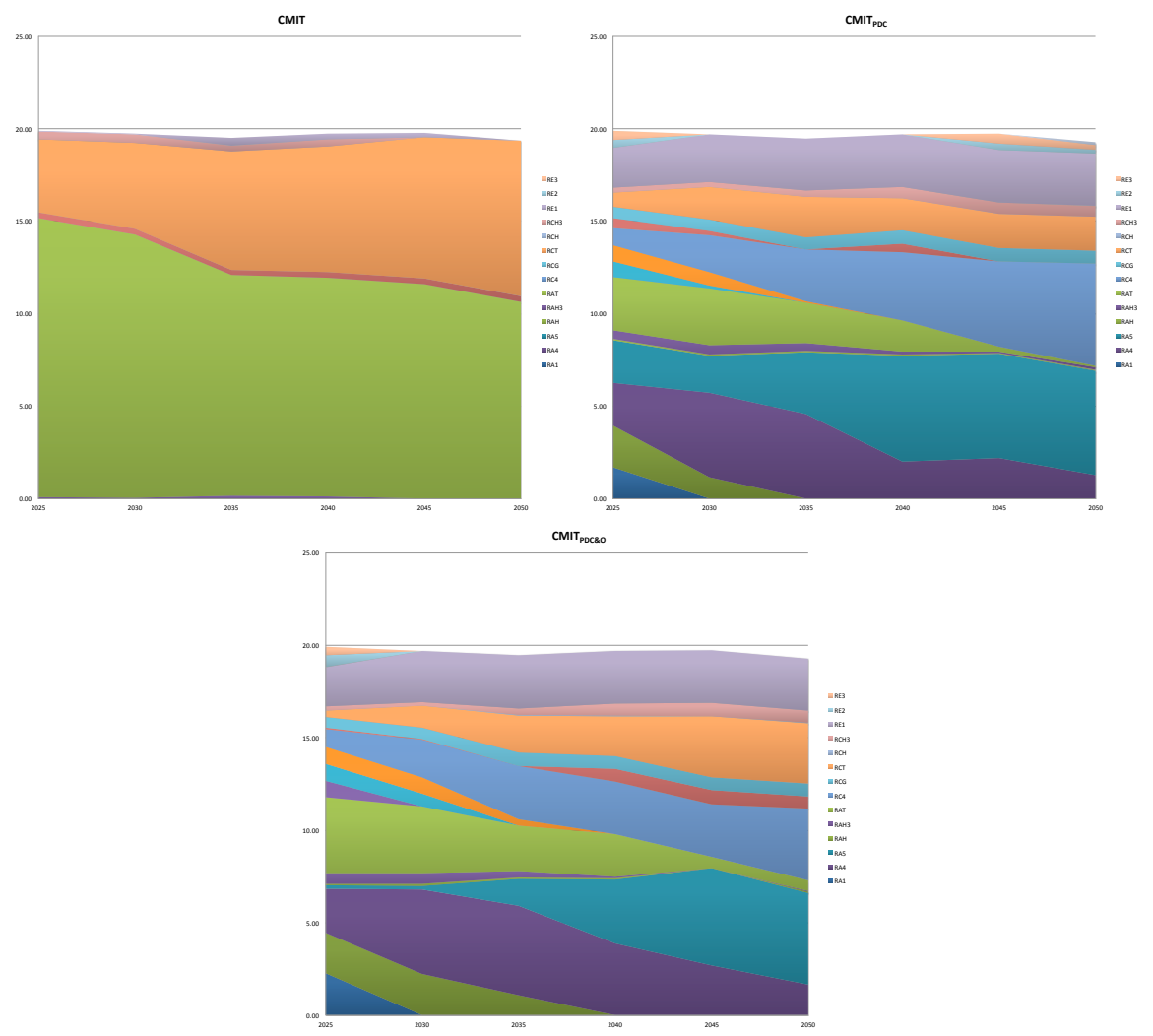

Figure 5: Evolution of heating activities in buildings (in PJ).

Finally, when smart systems are fully exploited, in scenario $C M I T_{P D C \& O}$, flexible loads from heat pumps and electric vehicles reach around $21 \%$ of total electricity consumption in 2050. The deployment of these smart grid options acts as positive vector for VREs penetration. The share of VRE generation is now around $61 \%$, to be compared to the $40 \%$ when smart options are not considered (see Figure 4). In that context imports are not needed anymore. This increase is due to the possible contribution of DREs to providing secondary reserve to cope with intermittency of Wind and solar generation. 


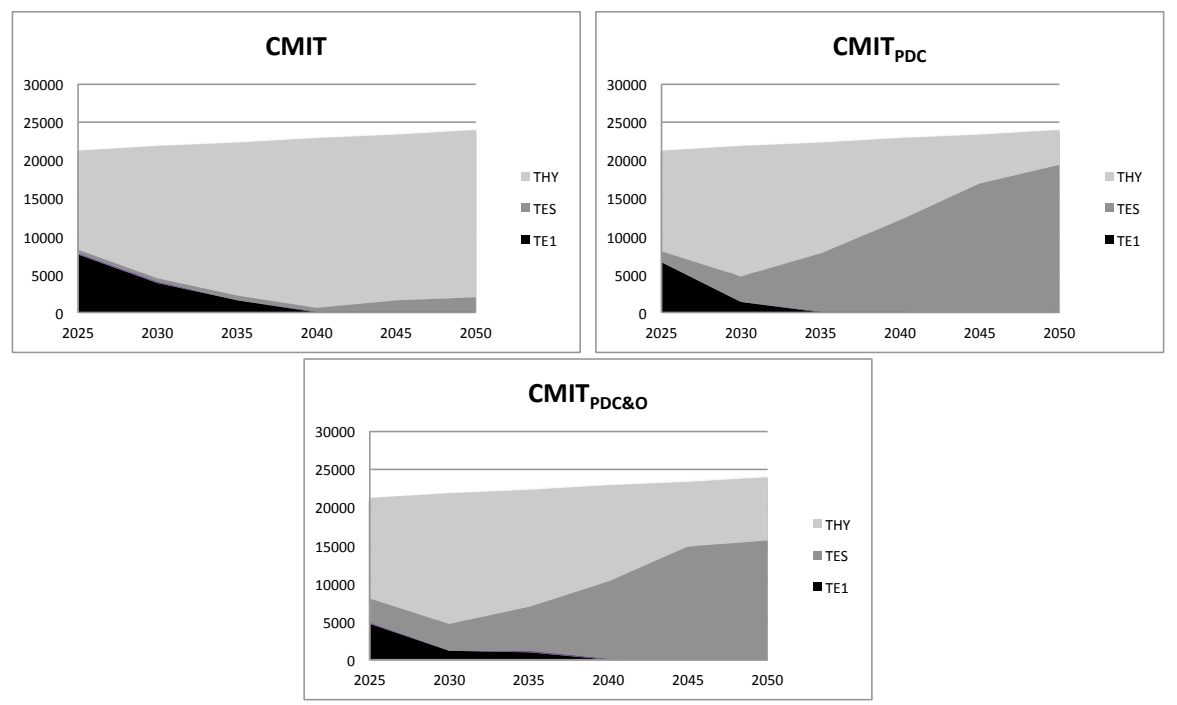

Figure 6: Evolution of transport activities (in tkmv/d).

\subsection{Power distribution options for $C M I T_{P D C \& O}$ scenario}

We now focus our analysis on the $C M I T_{P D C \& O}$ scenario only and we present the main impacts of flexible loads, PVs, electric vehicles, etc, on real power generation (Figure 7), reactive power compensation (Figure 9) and secondary reserve requirement (Figure 11). For real and reactive power generation we display associated load curves in Figure 8 and 10 , respectively.

In Figure 7, decentralized production corresponds uniquely to solar generation as indicated in Figure 4. Detailed loads displayed on Figure 8 show this solar contribution on day timeslices.

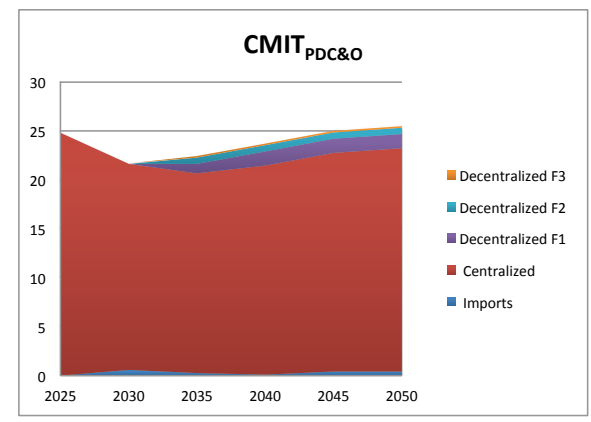

Figure 7: Real power generation converted energy equivalent (in PJ).

One notices on Figure 9 that reactive power is first compensated by flexible loads 

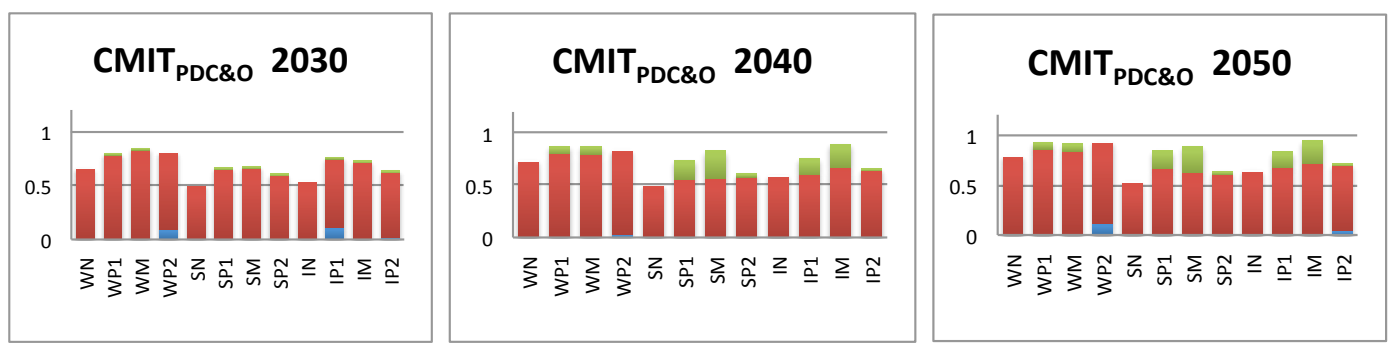

Figure 8: Real power generation (in GW) - Legend: Green for decentralized, red for centralized and blue for imports.

and then by PVs and centralized power plants.

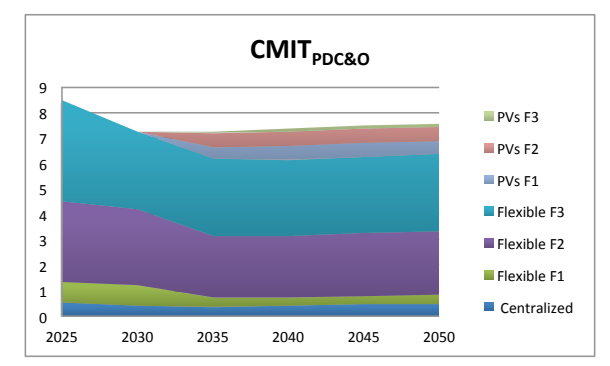

Figure 9: Reactive power compensation (in $\mathrm{PJ} / \mathrm{Y}$ ).
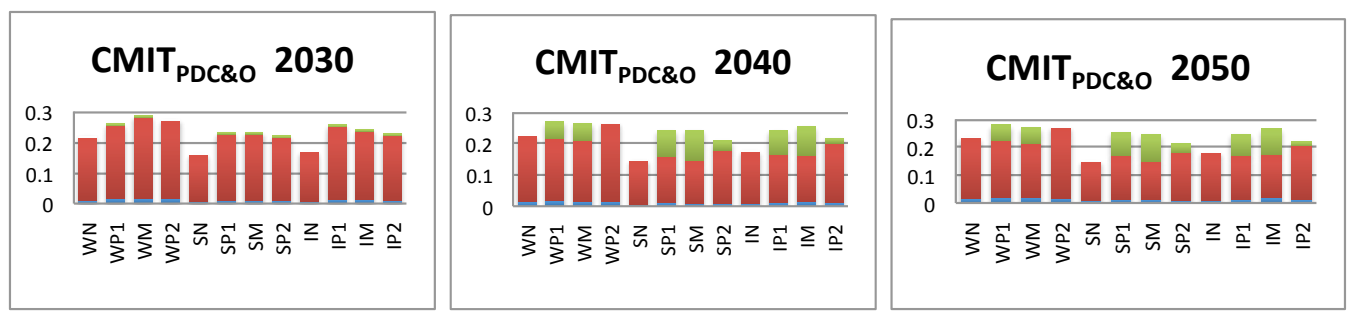

Figure 10: Load curve for Reactive power Generation (in GW) - Legend: Green for Pvs, red for Flexible and blue for Centralized.

Figure 11 confirms the key role played by EVs and flexible heating technologies for providing system secondary reserve. This shows that EVs and flexible loads will be facilitators for the transition of the energy system toward a low carbon economy.

\subsection{Implementing robustness with respect to uncertain energy prices}

We illustrate here the introduction of robustness in ETEM-SG when energy prices are uncertain. We assume that prices of oil-based energies (gazoline/diesel for transportation and fuel oil for heating) have a $50 \%$ variability while prices of coal, gas and 


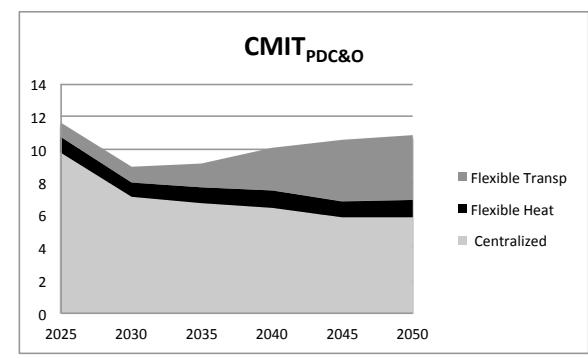

Figure 11: System reserve converted energy equivalent (in PJ).

electricity have a lower variability of $20 \%$. We apply robust optimization as described in Section 2.6 on the smart scenario, i.e., $C M I T_{P D C \& O}$. We first observe that the changes compared to the deterministic results presented in the previous section are not negligible but somehow limited. The reason is that the CMIT scenarios are already very constrained by the emissions limit, so the model has no much latitude to adapt the energy system and the technology portfolio to uncertain energy prices. Despite this, we observe an interesting behavior:

- First, as expected, the highest uncertainty being associated with oil-based energies, the main impact of robustness is to be observed on the transportation sector, in particular with a strongest penetration of EVs. In 2050 the share of EVs increases by $20 \%$ compared to the deterministic scenario.

- The second effect concerns the electricity sector whose production is directly impacted by uncertain prices. We notice an increase of electricity consumption of 1 PJ in 2050 combined with a significant growth of wind and solar generation. In 2050, 2 PJ (i.e., $7 \%$ of total production) are additionally produced augmenting the share of VRE generation to around $63 \%$. The increase of renewable generation is mainly used by EVs.

- A third non-expected consequence is the substitution of $50 \%$ of gas furnaces by oil ones in the appartement heating sector. First, the highest VRE generation gives more room to fossil energies in the satisfaction of the emissions constraint. In that context, the model favours technology diversification to reduce the risk related to uncertainty.

- Finally and more generally, in this analysis, as well as in the previous studies, one may observe a diversification effect, which reduces the risk related to uncertainty. 


\section{Conclusion}

In this paper we have described a complete regional energy model, ETEM-SG, which contains a new module devoted to the description of power distribution options and constraints. The model has been tested on a case study corresponding, in big strokes, to the "Léman region" in Switzerland. Computationally, it demonstrates that the approximation of a non-linear power distribution model by a linear one is efficient. The proposed iterative approach converges very rapidly to a fixed-point.

The experiment also shows that ETEM-SG captures the substantial help provided by DERs for a strong penetration of renewables. The interpretation of the three scenarios that have been simulated shows that:

- We first demonstrate that it is essential to handle power distribution constraints in such long-term analysis to produce realistic energy systems that are compatible with network stability requirements. We propose here a global approach that includes reactive power compensation, system secondary requirements, power distribution losses, etc, while classical approaches introduce some arbitrary constraints limiting artificially the proportion of VRE generation.

- The consideration of power distribution options and constraints does bring significative changes in technology choices, in the space heating and transport sectors. In general the electricity consumption and local production are reduced, when power distribution losses and costs are better represented.

- In the context of stringent emissions reduction policies, EVs with their batteries as well as flexible loads play a key role in the penetration of electricity-based technologies and intermittent productions. They facilitate the supply/demand balance for electricity by smoothing production and consumption. They also help significantly to the stability of the power distribution systems with their contribution to reactive power compensation and reserve requirements.

- Including robustification on energy prices in the design of scenarios amplifies the VRE penetration and leads to higher diversification in the technology portfolio. The proposed approach can handle in a same modelling exercise a large set of uncertainty sources (e.g., import prices, technology costs, technology efficiency and availability, etc) without increasing dramatically CPU time.

ETEM-SG can still be extended to include more constraints related to the distribution grid, in particular those related to primary (fast) reserve, that can be provided by battery packs, supercapacitors or flywheels, etc. ETEM-SG is also currently extended to include power transmission constraints for interconnected regional power systems. 


\section{References}

[1] Andersen A.N., Lund H. New CHP partnerships offering balancing of fluctuating renewable electricity productions. Journal of Cleaner Production 2007;15(3): pp. 288-293.

[2] Andrey C., F. Babonneau, A. Haurie and M. Labriet. Modélisation stochastique et robuste de l'atténuation et de l'adaptation dans un système énergétique régional. Application à la région Midi-Pyrénées, Natures Sciences Société, 23:133-149, 2015.

[3] Andrey C., F. Babonneau, A. Haurie, Time of Use (TOU) Pricing: Adaptive and TOU Pricing Schemes for Smart Technology Integration, Swiss Federal Office of Energy, Publication 291005, available online http://www.bfe.admin.ch/ forschungewg/02544/02809/index.html?lang=en\&dossier_id=06280, 2014.

[4] Babonneau F., M. Caramanis, A. Haurie, Modeling Distribution Options and Constraints for Smart Power Systems with Massive Renewables Penetration, Technical report ORDECSYS, submitted, 2015.

[5] Babonneau F., A. Kanudia, M. Labriet, R. Loulou and J.-P. Vial, Energy Security: a Robust Programming Approach and Application to European Energy Supply via TIAM, Environmental Modeling and Assessment, 17(1):19-37, 2012.

[6] Babonneau F., J.-P. Vial, and R. Apparigliato. Robust optimization for environmental and energy planning. In J.A. Filar and A. Haurie, editors, Handbook on Uncertainty and Environmental Decision Making, International Series in Operations Research and Management Science, pp. 79-126. Springer Verlag, 2010.

[7] Babonneau F., A. Haurie, G. J. Tarel and J. Thénié. Assessing the Future of Renewable and Smart Grid Technologies in Regional Energy Systems, Swiss Journal of Economics and Statistics, 2012, Vol. 148 (2), pp. 229-273.

[8] Ben-Tal, A., El Ghaoui, L., and Nemirovski, A. (2009). Robust optimization. Princeton: Princeton University Press.

[9] Blarke MB, Lund H. Large-scale heat pumps in sustainable energy systems: system and project perspectives. Thermal Science 2007;11(3):143-152.

[10] Bouckaert S., Mazauric V., Nadia Maïz, Expanding Renewable Energy by Implementing Demand Response, Energy Procedia, Vol. 61, 2014, pp.1844-1847.

[11] Bundesamt für Energie. Die Energieperspektiven für die Schweiz bis 2050, Energienachfrage und Elektrizitätsangebot in der Schweiz 2000 - 2050, 2012.

[12] Carlson D., A. Haurie, J.-P. Vial, and D.S. Zachary. Large-scale convex optimization methods for air quality assessment. Automatica, 40:385-395, 2004.

[13] ETEM http://www.ordecsys.com/en/etem 
[14] Drouineau M., N. Maïzi and V. Mazauric, Impacts of intermittent sources on the quality of power supply: The key role of reliability indicators, Applied Energy 116 (2014) pp. 333-343

[15] Farivar M., C. Clarkey, S. Low, M. Chandy, "Inverter VAR Control for Distribution Systems with Renewables", 2011 IEEE International Conference on Smart Grid Communication, pp. 457-462.

[16] Fourer, R., B. W. Kernighan . AMPL: A Modeling Language for Mathematical Programming. 2002. Duxbury Press.

[17] Fragnière E. and A. Haurie, A Stochastic Programming Model for Energy/Environment Choices under Uncertainty, International Journal of Environment and Pollution, Vol. 6, No. 4-6, 1996, pp. 587-603.

[18] Fragnière E. and A. Haurie, MARKAL-Geneva: A Model to Assess EnergyEnvironment Choices for a Swiss Canton, Chap. 3 in C. Carraro and A,. Haurie eds. Operations Research and Environmental Management, Fondazione Eni Enrico Mattei, Economics Energy Environment, Kluwer Academic Press, 1996.

[19] Fishbone, L.G., Abilock, H. MARKAL, a linear-programming model for energy systems analysis; technical description of the BNL version, Energy Research 5: 353-375, 1981.

[20] Gelsler K., the Relationship between smart grids and smart cities, IEEE newsletter, May 2013.

[21] Giffinger, R., Fertner, C., Kramar, H., Kalasek, R., Pichler-Milanovic, N., and Meijers, E. (2007). Smart Cities: Ranking of European Medium-Sized Cities. Vienna, Austria: Centre of Regional Science (SRF), Vienna University of Technology.

[22] Harrison, C., Eckman, B., Hamilton, R., Hartswick, P., Kalagnanam, J., Paraszczak, J., and Williams, P. (2010). Foundations for Smarter Cities. IBM Journal of Research and Development, 54(4).

[23] Haurie A., J. Kubler, A. Clappier and H. van den Bergh, A Meta-modeling approach for integrated assessment of air quality policies, 2002, Environmental Modeling and Assessment. Vol. 9, pp. 1-12, 2004.

[24] Hill D. , editor. 1996. The Baked Apple? Metropolitan New York in the Greenhouse. Annals of The New York Academy of Sciences 790.

[25] Howells Mark, Holger Rogner, Neil Strachan, Charles Heaps, Hillard Huntington, Socrates Kypreos, Alison Hughes, Semida Silveira, Joe DeCarolis, Morgan Bazillian, Alexander Roehrl, OSeMOSYS: The Open Source Energy Modeling System: An introduction to its ethos, structure and development, Energy Policy, Vol. 39, issue 10, Oct. 2011, pp. 5850-5970. 
[26] Karnouskos, S., (2011), Cyber-Physical Systems in SmartGrid, Proceedings 9th IEEE International Conference on Industrial Informatics (INDIN). http://diktio.dyndns.org/files/2011_INDIN.pdf.

[27] Loulou R. and Labriet M., ETSAP-TIAM, the TIMES integrated assessment model Part 1: Model structure. Computational Management Science, Vol. 5, pp.740,2009.

[28] Lund H, Andersen AN, Østergaard PA, Mathiesen BV, Connolly D. From electricity smart grids to smart energy systems - a market operation based approach and understanding. Energy 2012;42(1):96e102.

[29] Lund H. Large-scale integration of wind power into different energy systems. Energy 2005;30(13): pp. 2402-2412.

[30] Lund H, Kempton W. Integration of renewable energy into the transport and electricity sectors through V2G. Energy Policy 2008;36(9):3578-3587.

[31] Lund $\mathrm{H}$, Münster E. Integrated transportation and energy sector $\mathrm{CO}_{2}$ emission control strategies. Transport Policy 2006;13(5):426-433.

[32] Ntakou E. and M. Caramanis, Proceedings ... IEEE, Price Discovery in Dynamic Power Markets with Low-Voltage Distribution-Network Participants, 2013.

[33] Messner S., Strubegger M. Model-based decision support in energy planning, International Journal of Global Energy Issues, Vol. 12(1-6):196-207, 1999.

[34] ORDECSYS, Réseaux intelligents de transport/transmission de l'électricité en Suisse. Swiss Federal Office of Energy, 2013.

[35] Rosen, J.B., Existence and uniqueness of equilibrium points for concave n-person games. Econometrica, Vol. 33 (3) pp. 520-534., 1965.

[36] Soyster, A. L. Convex programming with set-inclusive constraints and applications to inexact linear programming. Operations Research, 21, 1154-1157, 1973.

[37] M. Welsch, M. Howells, M. Bazilian, J.F. DeCarolis, S. Hermann, H.H. Rogner, Modelling elements of Smart Grids - Enhancing the OSeMOSYS (Open Source Energy Modelling System) code, Energy, Vol. 46, No 1, October 2012, pp. 337350 .

[38] Wene C.-O., The Optimum Mix of Conservation and Substitution: An Example from Retrofitting of Old Buildings, Energy Research, Vol. 4, pp. 271-282, 1980.

[39] Wene C.-O., O. Andersson, Long-range community energy planning: case study Jönköping (in Swedish), EFN/AES, Stockholm, 1983.

[40] Wene C.-O., B. Ryden, A comprehensive energy model in the municipal energy planning process, European Journal of Operational Research, Vol. 33:2, pp. 212$222,1988$. 
[41] T. Agarwal and S. Cui. Noncooperative games for autonomous consumer load balancing over smart grid. In Game Theory for Networks. Third International ICST Conference, GameNets 2012, Vancouver, BC, Canada, May 24-26, 2012, Revised Selected Papers, volume 105 of Lecture Notes of the Institute for Computer Sciences, Social Informatics and Telecommunications Engineering, pages 163-175. Springer Berlin Heidelberg, 2012. 